\title{
Using Social Media in an Open Distance Learning Teaching Practice Course
}

\author{
Micheal M van Wyk \\ Department of Curriculum and Instructional Studies, \\ School of Teacher Education, College of Education, \\ University of South Africa, Pretoria \\ vwykmm@unisa.ac.za
}

Doi:10.5901/mjss.2014.v5n4p370

\begin{abstract}
Using social media to support educational endeavors leverages the benefits of in-person learning communities with the benefits of using technology to support student engagement. This paper explores the use of social media to support economics education student teachers' engagement in teaching practice at an open distance learning institution. Only sixty nine student teachers $(n=369)$ registered for the SDECOON blog (subject didactics economics), which was a pilot study to use blogging as an educational tool to support them during teaching practice placements for the following academic year. Only Economics education students were invited by e-mail message, blog and discussion forum as announcements on myUnisa webpage to complete an online social media survey (SMS). The intent of this research was to provide some insight into the impact the use of social media can have on the level of student teachers engagement in their learning. The findings indicated that there was a positive correlation between the frequency of student use of social media and their relationship with their peers and instructors as well as how they describe the overall quality of instruction and the preservice teaching practice programme.
\end{abstract}

Keywords: social media in an open distance learning teaching practice course

\section{Introduction}

The challenge for institutions of higher learning is to make provision for a technology integrated teaching and learning mode other than the conventional face-to-face method to accommodate the digital natives and empowering the digital immigrants. We cannot teach as we were trained during the 1980's compare to the current student profile which most of them born during the 1990's. Indeed, the internet and mobile technologies have questioned our assumptions about how learning and teaching are constituted. They have challenged us to develop new ways of conceiving space/place, time, immediacy, identity and togetherness/community. These students are the Net Generation or the digital natives. These digital natives bring new challenges to the teaching and learning environment. Shortly after the turn of the millennium, a new way to characterize the change in how the digital natives' as well digital immigrants interacted with websites began to appear. In the last seven years, the "Web 2.0" and Web 3.0 technology became popular characterization of websites that allowed digital users to interact with each other as contributors to a website's content. These new features that facilitated user engagement, collaboration, and interactive information sharing were a significant departure from traditional websites that were limited to the passive viewing of information. In particular, the Web 2.0 website has now been applied to a plethora of social media websites that rely heavily on the active engagement of their users to create, manipulate, and share content. The question is: how are we responding to this challenge and how can they create enabling environments for effective online teaching and learning spaces? Research studies have indicated the learning effect of teaching with blogs for online learners (McLoughlin and Lee, 2007; van Wyk, 2013a). This paper explores the use of social media to support economics education student teachers' engagement in teaching practice at an open distance learning institution.

\section{Using Social Media in Teaching and Learning}

Scholars argue that social media is characterized as Web 2.0-based e-learning resources that emphasize active participation, connectivity, collaboration, and sharing of knowledge and ideas among users (van Wyk, 2013a; Killeavy and Moloney, 2010; McLoughlin and Lee, 2007). According the authors, social media resources can be divided into three distinct categories. The first category emphasizes content sharing and organizing sites. The second social media 
category encompasses content creation and editing websites such as Blogger, Google Docs, Wikipedia, and WordPress. The third category includes social network sites (SNS) like Facebook, Ning, MySpace, Twitter, and Orkut, that serve as online communities that enable users to connect with old or new friends, and share ideas and resources. These social media can be very useful as e-learning tools which can serve for an educational purpose, and this case Van Wyk (2013b) uses blogs as a supportive tool for economics education students' engagement during their teaching practice placements. Several authors collaboratively defined social network sites as web-based services that allow individuals or groups to (1) construct a public or semi-public profile within a bounded system, (2) articulate a list of other users with whom they share a connection, and (3) view and traverse their list of connections and those made by others within the system (Boyd and Ellison, 2007; van Wyk, 2013a). On the other hand, the initial objective of these sites was purely social as they provided a means to connect with old friends and make new friends. Emanating from this flow, several research studies conducted thus far, which indicates that students have integrated SNS into their academic life as a tool for communicating with classmates about course-related topics, coordinating study groups, and collaborating on assignments (Salaway, Caruso, Nelson, and Ellison, 2008; van Wyk, 2013b).

Using social media to support educational endeavors leverages the benefits of in-person learning communities with the benefits of using technology to support student engagement. Previous research has indicated that learning communities can have a positive impact on student learning and the level of university student interaction and cooperation (van Wyk, 2013b; Panda 2010). Along with supporting the formation of professional learning communities, social media has the potential to reap the benefits of using technology for academic purposes (Killeavy and Moloney, 2010; Zhao and Kuh, 2004). Research has indicated that there is a positive relationship between academic uses of technology and the occurrences of active and collaborative learning, and the frequency of student-faculty interactions (Laird and Kuh, 2005). Both of these benefits are considered to contribute to the level of student engagement, which has been determined to significantly impact student success (Kuh, 2001a).

The dynamic nature of these social media tools allow learners to become active participants or co-producers rather than passive consumers of content, so that learning is a participatory and social process (van Wyk 2013b; McLoughlin and Lee, 2007). In addition to heightening student engagement, the effective use of social media resources can result in a constructivist learning environment which allows students to share their interpretations of the course content, and utilize their individual life experience and multiple intelligences, while working as a part of a collaborative team (Baird and Fisher, 2006). As educational resources, social media tools can also be used to differentiate the learning process. The plethora of available social media resources allows learners to select and share learning materials that best meet their learning style and interests. According to van Wyk (2013a) by selecting multiple social media tools such as blogs or wikis, lecturers can create differentiated learning paths that can be bundled together to create dynamic learning spaces to accommodate diverse populations. Moreover several studies indicated that these personalized and customized learning experiences may be better suited to address the diverse needs of today's digital natives (Baird and Fisher 2006; Christensen, Horn, and Johnson 2008). Additionally, the public nature of most social media tools can also be used to support authentic learning opportunities. While private learning spaces can often be secured when using these public tools, remaining in the public sphere allows learners to benefit from the contributions of other learners outside of the confines of the course, as well as with noted lecturers within these content areas. The dynamic and engaging nature of many social media tools may also encourage students to expend more time and energy on their academic activities as a consequence of the collaborative, constructivist, and authentic learning opportunities they can create (Kennedy 2000, van Wyk 2013a). As a result, when students are engaged there is a greater likelihood of increased rates of student persistence and improved academic achievement (Makri and Kynigos 2007; Kuh, Kinzie, Cruce, Shoup, and Gonyea 2007).

\section{Student Engagement with Social Media Platforms}

Increased attention to student engagement and active learning strategies have become particularly relevant in today's $21^{\text {st }}$ century classroom environments. Chernay (2008) agreed that to be actively involved requires students to use higher order thinking including analysis, synthesis and evaluation. Moreover, Panda (2010) and Laird and Kuh (2005) concurred that student engagement represents both the time and energy students invest in educationally purposeful activities These activities include times spent interacting with their peers and lecturers as well as time engaging in active and collaborative learning activities (Kennedy 2000; Laird and Kuh, 2005). These items are essential not only because previous research has shown that these factors are positively related to academic success in college and university, but also because these elements represent student behaviors and activities that institutions can influence to varying degrees 
through teaching practices and creating other conditions that foster student engagement (Killeavy and Moloney 2010). Consequently, by institutionalizing practices that increase the time and energy students spend engaging in these types of activities, such as in this study, student teachers engagement in using social media through blogspace with a supportive myUnisa learning management platform may increase. This increase in student teacher engagement may also increase the likelihood that students will persist in their teaching practice course. Increased academic persistence would inevitably have a favorable impact on their continued progress toward degree completion and promote academic success in comparison to the low engaged student (van Wyk 2013b; Kennedy 2000; Umbach and Wawrzynski 2005). Moreover, the nature of student-faculty interaction can have significant repercussions for student motivation and involvement, as having positive and personal interactions with lecturers can enhance a student's intellectual commitment while providing the support needed to help students overcome academic challenges (van Wyk 2012; Chickering and Ehrmann 1996). Social media can be used to enhance and increase the number of interactions students have with their lecturers by overcoming the barriers of time and location. As a result, the opportunities for students to ask questions, as well as get resources and feedback from their lecturers may increase performance levels. In addition to often being more convenient, Chickering and Ehrmann (1996) note that technology can also create a less intimidating means of student-faculty interactions than asking questions in front of a large lecture hall of classmates.

More importantly, student engagement is enhanced when students have the opportunity to work with their peers, share ideas and resources, and reflect on the different perspectives their fellow students bring to class (Panda 2010; Baird and Fisher. 2006; Chickering and Gamson 1987). Social media provide a great benefit to the current generation of university and college students as these tools were created with the primary intent of facilitating sharing, discussion, and collaboration. As noted earlier, social media can be used to support the creation of supportive social networks and learning communities. The perception that a student is a part of a caring and supportive campus environment not only reduces feelings of isolation, but has been identified as a factor that contributes to increasing persistence rates and academic success for at-risk students (Enriquez. 2012; Kennedy 2000).

Several scholars argue that the interactive nature of many Web 2.0 social media tools allows learners to become active participants who co-construct the learning experience with their peers and lecturer, as they share and reflect on their individual interpretations and experiences to create an educational 'mash-up' (Panda 2010; Baird and Fisher 2006; McLoughlin and Lee 2007). While previous research has noted that there is a positive relationship between the use of educationally purposeful social media and student engagement (Laird and Kuh 2005; Zhao and Kuh 2004), a reexamination of these findings is needed not only because of the newness of some of these Web 2.0 resources, but also because many of these social media tools engage users in fundamentally different ways from previous education technology resources. More importantly, the proliferation of these resources, which can be accessed via laptops and mobile devices during class as well as before and after, highlights how the use of many of these social media resources has become a pervasive force in the lives of today's students (van Wyk 2013b; Salaway et al. 2008).

\section{Research Methodology}

\subsection{Contetx of the study}

The teaching practice office (TPO) which is a division of the School for Teacher Education is responsible for placement of student teachers. The TP unit is responsible for organising and supervision student teachers in the teacher education programmes. All students registered for the Postgraduate Certificate in Education (PGCE) programmes are expected to do twenty five percent $(25 \%)$ teaching practice of qualification (PGCE 10 weeks per yearly module). The College of Education (CEDU) produces currently fifty five percent (55\%) of teachers for the South African education system and thirteen percent (13\%) internationally, student teacher enrolment is an approximately 22000 and this have huge challenges to the administration and learning management systems of the TP unit in the CEDU. School visits for on-site assessment are compulsory but not enough and other means must be develop to support students during the teaching practice. All registered PGCE economics education (SDECOON) students were linked to the module (subject didactics Economics module) on myUnisa (Learning Management System), during the ODL teaching practice placements, for this study.

\subsection{Research questions}

The following research questions were formulated for the purpose of conducting this study: 
- How aften are participants' frequency use of a variety of social media resources to discuss/complete the economics assignment or to work with classmates outside of class to prepare class assignments? and

- How are the relationships with fellow students and how they would evaluate the quality of instruction they received during the course.

\subsection{Participants}

The participants in the study were six hundred and sixty three Economics education student teachers $(n=369)$ who enrolled in the Postgraduate Certificate of Education (PGCE) initial teacher education programme at an open distance learning (ODL) institution of higher learning. Consequently, to gain entry into the initial teacher education programme, candidates must have previously completed an undergraduate degree with a record of high academic achievement. An invitation by a short messages service (sms) was send to these student teachers to register on the blog, Economics subject didactics. Only three hundred and sixty nine student teachers registered for the blog, which was using social media as an educational tool to support them during teaching practice placements.

\subsection{Data collection and procedures}

Economics education student teachers were invited by e-mail message, blog and announcement on myUnisa to complete an online social media survey (SMS), that mimicked the questions posed on these online social and educational tools. It was designed with the sole purpose of assessing the extent to which students are engaged in empirically derived good educational practices. Consequently, the results from the SMS have been used to create institutional, national and international benchmarks of effective educational practices that support student engagement. Of particular interest to this paper, participants were asked to describe their frequency of use of a variety of social media resources to discuss/complete the economics assignment or to work with classmates outside of class to prepare class assignments, their relationships with their fellow students and how they would evaluate the quality of instruction they received during the course. The questions inquiring about the students' frequency of use of social media resources provided examples that included e-mail, blogs, discussion forums, and wikis are common social media resources. The myUnisa was created as a learning management system (LMS) to communicate means to facilitate interaction and communication between the college, staff, and students that comprise the College of Education at the University of South Africa.

\subsection{Reliability and validity}

The reliability and validity test $(p<.879)$ of the questionnaire for this study was established. All questions included were closely modeled on the format of the online Social Media Survey (SMS).

\subsection{Ethical clearance}

Before the researcher could begin with the study, consent was obtained from the students. The researcher explained the purpose of the study. Further, then the purpose of confidentiality to the participants was explained.

\section{Results}

Of the 1134 students enrolled in the preservice teaching practice course, 369 completed the student engagement survey. To note the frequency of use of a variety of social media resources to discuss/complete an assignment or to work with classmates outside of class to prepare class assignments the participants were asked to indicate if they used e-mail, blogs, discussion forums, wikis, very often, often, sometimes or never (See table 1). While the majority of the respondents indicated that they had 'often' used an online media to work with classmates outside of class there was only a small majority that indicated that they 'sometimes' used online media to discuss or complete assignments.

\subsection{Used of social media to prepare and complete assignments}

In this question was asked how aften are participants' frequency use of a variety of social media resources to 
discuss/complete the economics assignment or to work with classmates outside of class to prepare class assignments.

Table 1. Frequency of Social Media Use

\begin{tabular}{|c|c|c|c|c|c|c|}
\hline Survey Question & Means & SD & Very often & Often & Sometimes & Never \\
\hline $\begin{array}{c}\text { Used online media } \\
\text { (e-mail, discussion forums, blogs, wikis.) to work with } \\
\text { classmates outside of class to prepare class assignments. }\end{array}$ & 3.68 & .341 & $25.3 \%$ & $34.9 \%$ & $29.8 \%$ & $10 \%$ \\
\hline $\begin{array}{l}\text { Used online media } \\
\text { (e-mail, discussion forums, blogs, wikis.) to discuss or complete } \\
\text { an assignment. }\end{array}$ & 3.11 & .653 & $21.9 \%$ & $32.3 \%$ & $34.2 \%$ & $11.5 \%$ \\
\hline
\end{tabular}

With reference to Table 1, the majority of respondents (60.2\%) indicated that they often (34.9\%) to very often (25.3\%) used online media such as e-mail, discussion forums, blogs, and wikis to work with classmates outside of class to prepare class assignments. on the other hand, it shows that sometimes (34.2\%) and often (32.3\%) used online media (e-mail, discussion forums, blogs, wikis.) to discuss or complete an assignment.

To capture the nature of their relationships with their fellow students and instructors, the participants were asked to select a number from one to seven that best represents the quality of their relationships with people in the teacher education programme (Table 2).

\subsection{Student-Lecturer Relationship Quality}

When asked to evaluate the quality of instruction they received and the overall program quality, the participants were asked to indicate if the quality was excellent, good, fair or poor (See table 3). For both questions, the majority of the participants indicated that they felt the quality of instruction and the overall program quality was 'good'.

To determine if there was a relationship between the variables a series of correlations were completed. The analysis highlighted that there were statistically significant relationships between the frequency of use of social media resources and how the participants described the quality of instruction and overall program quality (See table 3).

Table 3. Instruction/Program Quality

\begin{tabular}{|c|c|c|c|c|c|c|}
\hline \hline Survey Question & Means & SD & Excellent & Good & Fair & Poor \\
\hline $\begin{array}{c}\text { Overall, how would you evaluate the quality of instruction you have } \\
\text { received in the teacher education programme? }\end{array}$ & 3.76 & .214 & $22.7 \%$ & $56.1 \%$ & $17.8 \%$ & $3.3 \%$ \\
\hline \hline $\begin{array}{c}\text { Overall, how would you evaluate your entire educational } \\
\text { experience in the teacher education programme? }\end{array}$ & 3.82 & .262 & $24.9 \%$ & $51.7 \%$ & $18.9 \%$ & $4.5 \%$ \\
\hline
\end{tabular}

Respondents indicated that there was a good relationship (56.1\%) between the instruction and teacher education programme. Furthermore, good educational experience in the teacher education programme was experienced by them regarding the quality of instruction and overall program quality.

\subsection{Social Media Use and Instruction/Program Quality}

Table 4 . Correlation of Frequency of Social Media Use and Instruction/Program Quality

\begin{tabular}{|c|c|c|c|}
\hline & & $\begin{array}{l}\text { Overall, how would you evaluate } \\
\text { your entire educational experience } \\
\text { in the teacher education program? }\end{array}$ & $\begin{array}{l}\text { Overall, how would you evaluate the } \\
\text { quality of instruction you have received } \\
\text { in the teacher education program? }\end{array}$ \\
\hline \multirow{2}{*}{$\begin{array}{c}\text { Used an online medium } \\
\text { media (e-mail, discussion forums, } \\
\text { blogs, wikis.) to discuss or complete } \\
\text { an assignment. }\end{array}$} & $\begin{array}{l}\text { Pearson } \\
\text { Correlation }\end{array}$ & $.151^{* *}$ & $.123^{* *}$ \\
\hline & $\begin{array}{c}\text { Sig. } \\
\text { (2-tailed) }\end{array}$ & .011 & .009 \\
\hline \multirow{2}{*}{\begin{tabular}{|c||} 
Used online media media \\
(e-mail, discussion forums, blogs, \\
wikis.) to work with classmates outside \\
of class to prepare class assignments.
\end{tabular}} & $\begin{array}{l}\text { Pearson } \\
\text { Correlation }\end{array}$ & $.123^{*}$ & $.151^{\star *}$ \\
\hline & $\begin{array}{c}\text { Sig. } \\
\text { (2-tailed) }\end{array}$ & .024 & .005 \\
\hline
\end{tabular}

${ }^{*}$ Correlation is significant at the 0.05 level (2-tailed). ${ }^{* *}$ Correlation is significant at the 0.01 level (2-tailed). 
In an attempt to understand the correlation between social media use and student teacher perceptions of their relationship with their peers, a Spearman's rho correlation was performed. While the results indicated that there was a statistically significant relationship between the frequency of social media use to work with classmates outside of class and how the teacher candidates characterized their relationship with their peers, a statistically significant correlation was not apparent when examining the frequency of social media use to discuss or complete assignments (See table 5).

Table 5 . Correlation of Frequency of Social Media Use and Relationships with Other Student Teachers

\begin{tabular}{|c|c|c|}
\hline \hline \multicolumn{2}{|c|}{} & Relationships with other student teachers \\
\hline \hline $\begin{array}{c}\text { Used online media } \\
\text { media (e-mail, discussion forums, blogs, wikis.) to work } \\
\text { with classmates outside of class to prepare class } \\
\text { assignments. }\end{array}$ & $\begin{array}{c}\text { Spearman's } \\
\text { rho Correlation } \\
\text { Coefficient }\end{array}$ & $.121^{\star *}$ \\
\cline { 2 - 3 } $\begin{array}{c}\text { Used an online medium } \\
\text { media (e-mail, discussion forums, blogs, wikis.)to discuss } \\
\text { or complete an assignment. }\end{array}$ & $\begin{array}{c}\text { Sig. (2-tailed) } \\
\text { rho Corman's } \\
\text { Coefficient }\end{array}$ & .047 \\
\cline { 2 - 3 } & Sig. (2-tailed) & .089 \\
\hline
\end{tabular}

${ }^{\star *}$ Correlation is significant at the 0.01 level (2-tailed).

Similar to the previous correlation analysis, the results indicated that there is a statistically significant correlation between the frequency of social media use to work with classmates outside of class and the teacher candidates' characterization of their relationship with their instructors. Once again the same correlation was not apparent when examining the frequency of social media use to discuss or complete assignments and their description of their relationship with their instructors (See table 6).

\subsection{Social Media Use and Relationships with Instructors}

Table 6. Correlation of Frequency of Social Media Use and Relationships with Instructors

\begin{tabular}{|c|c|c|}
\hline \hline \multicolumn{2}{|c|}{} & Relationships with instructors \\
\hline \hline \multirow{2}{*}{$\begin{array}{c}\text { Used online media } \\
\text { medassmates outside of class to prepare class assignments. }\end{array}$} & Searson Correlation & $.129^{\star}$ \\
\cline { 2 - 3 } & Sig. (2-tailed) & .034 \\
\hline \hline $\begin{array}{c}\text { Used an online medium } \\
\text { (media (e-mail, discussion forums, blogs, wikis.) to discuss or } \\
\text { complete an assignment }\end{array}$ & Pearson Correlation & .102 \\
\cline { 2 - 3 } & Sig. (2-tailed) & .095 \\
\hline
\end{tabular}

${ }^{*}$ Correlation is significant at the 0.05 level (2-tailed).

\section{Discussion}

Findings revealed that a greater number of student teachers using social media tools to interact with their classmates outside of class to prepare assignments rather than using these same tools to discuss or complete assignments. These findings support previous research that indicated that students tend to use the Internet to communicate with other students (Enriquez 2012; van Wyk 2013b; Hu and Kuh 2001; Laird and Kuh 2005) more so than to actually complete their coursework. Consequently, it is not surprising that there was a correlation between the frequency of social media use and the nature of the relationship teacher candidates had with their peers. Moreover, van Wyk (2013a) posits that using social media to interact with their peers may provide students with greater opportunities to get to know their peers and in turn develop a positive relationship with them. In addition (Killeavy and Moloney 2010) to enhancing the perception of a supportive campus environment, having a positive relationship with their peers can be essential to the creation of learning communities where students are at ease with one another so that they may work collaboratively, freely share opinions and respond constructively to the ideas of their fellow students. These conditions are a necessary prerequisite for the critical thinking that supports learning to occur (Enriquez 2012; van Wyk 2013b). Nonetheless, while this study did not specifically ask the participants if they used social media to interact with their instructors, there appears to be a correlation between the frequency of social media use to interact with their classmates outside of class to prepare 
assignments and the nature of the relationship teacher candidates have with their instructors (Killeavy and Moloney 2010; Kuh 2001a). This surprising finding may support Laird and Kuh's (2005) conclusion that engagement in one area, such are student-faculty engagement, often goes hand-in-hand with engagement in other areas. This notion suggests that engaged students will take advantage of all of the available resources, including technological and social media resources (Kennedy 2000), to enhance their educational experience. Unfortunately, the reverse assumption is that low engaged students may fail to capitalize on the opportunities that social media provides to increase their level of engagement. Regardless, student-faculty interaction is noted as one of the key contributors to high student engagement (Kuh 2001b; Kuh et al. 2007) and using social media to enhance student-faculty relationships can have positive educational consequences (van Wyk 2013b; Panda S 2010).

\section{Conclusion}

The intent of this research was to provide some insight into the impact the use of social media can have on the level of student teachers engagement in their learning. The findings indicated that there was a positive correlation between the frequency of student use of social media and their relationship with their peers and instructors as well as how they describe the overall quality of instruction and the preservice teaching practice programme. The results of this study should be interpreted with caution due to the following limitations. First, a bias may exist because of the self-selected sample of Economics education students. Second, the researcher who wants to better explore the phenomenon should develop more elaborate scales of research constructs for an ODL context. Lastly, preservice student teachers generally have a long history of positive educational experiences and high academic achievement. Thus, the conclusions may not be generalizable to the general undergraduate student teacher population. Despite this, the results may be useful to lectuters that work primarily with student teachers enrolled in professional programmes. The reliability and validity of the questionnaire used in this study was established. Similar to the impact of the SMS, it is hoped that these result may be used to inform future research and eventually lecturer and institutional practices that capitalize on the benefits of using social media to support student engagement. Once the higher education community has a better understanding of how and why students are using social media resources as part of their educational experience, this information can be used to support lecturer professional development and the creation of institutionally supported social media resources.

\section{Future Research and Recommendations}

The greatest challenge to future research and the usefulness of these results is in understanding the use or lack of use of social media resources by low engaged students. The conclusion that highly engaged students may be high users of educationally purposeful social media resources should not be astonishing to educators. There is a natural tendency for highly engaged students to make good use of all of the educational resources that are available to them. The challenge is to determine how the educational community can leverage the social nature of these resources to support increased levels of interaction between high and low engaged students. Further it is recommended that research is needed that because peers are very influential to student learning and values development, educational intuitions should attempt to harness and shape this influence so that it is educationally purposeful and helps to reinforce academic expectations. It is recommended that the benefits of using social media to support teaching and learning will not be fully realized until there is a better understanding of how the social nature of these social media resources can be used to entice low engaged or disengaged students to interact in educationally purposeful ways with their high-engaged peers and instructors so that it contributes to the success of students.

\section{Acknowledgement}

The author acknowledged the financial contributions made by the National Research Foundation of South Africa (NRF) for Grant funding. Acknowledgement is given to the Economics education students who voluntarily participated in this research study. Lastly, the quality of language revision work done by university language editing unit is highly appreciated. Any opinions, findings, and conclusions expressed in this paper are those of the author and do not reflect the views of the NRF or the Department of Curriculum and Instructional studies in the College of Education. 


\section{References}

Baird DE, Fisher M. 2006. Neomillennial user experience design strategies: Utilizing social networking media to support "Always On" learning. Journal of Educational Technology Systems, 34(1), 5-32.

Boyd D, Ellison NB. 2007. Social network sites: Definition, history, and scholarship. Journal of Computer-Mediated Communication, 13(1).

Chemay ID. 2008. "The Effects of Active Learning on Students' Memories for Course

Content," Active Learning in Higher Education, Vol. 9, No.2, p. 152.

Chickering AW, Ehrmann SC. 1996. Implementing the seven principles: Technology as lever. American Association for Higher Education and Accreditation Bulletin, 49(2), 3-6.

Chickering AW, Gamson ZF. 1987. Seven principles for good practice in undergraduate education. American Association for Higher Education and Accreditation Bulletin, 39(7), 3-7.

Christensen CM, Horn, MB, Johnson CW. 2008. Disrupting class: How disruptive innovation will change the way the world learns. New York, NY: McGraw-Hill.

Deibert R., Palfrey JG, Rohozinski R., Zittrain J. 2008. Access denied: The practice and policy of global Internet filtering. Cambridge, MA: The MIT Press.

Enriquez J. 2012. Being (t)here: mobilising 'mediaspaces' of learning. Learning, Media and Technology, 1-18

Hu S, Kuh GD. 2001. Computing experience and good practices in undergraduate education: Does the degree of campus wiredness matter?, Annual Meeting of the American Educational Research Association. Seattle.

Kennedy C. 2000. Implications for new pedagogy in higher education: Can online technology enhance student engagement and learning? (Doctoral dissertation, University of California at Berkeley). Retrieved ERIC database. (ED443382)

Killeavy M, Moloney A 2010. Reflection in a social space: Can blogging support reflective practice for beginner teachers. Teaching and Teacher Education, 26:1070-1076.

Kuh GD. 2001a. Assessing what really matters to student learning: Inside the National Survey of Student Engagement.Change, 33(3), 10-17.

Kuh GD. 2001b. The National Survey of Student Engagement: Conceptual framework and overview of psychometric properties. Bloomington, IN: Center for Postsecondary Research.

Kuh GD, Kinzie J, Cruce T, Shoup R., Gonyea RM. 2007. Connecting the dots: Multi-faceted analyses of the relationship between student engagement results from the NSSE, and the institutional practices and conditions that foster student success. Bloomington, IN: Center for Postsecondary Research.

Laird TFN, Kuh GD. 2005. Student experiences with information technology and their relationship to other aspects of student engagement. Research in Higher Education, 46(2), 211-232.

Makri K, Kynigos C 2007. The role of blogs in studying the discourse and social practices of mathematics teachers. Educational Technology and Society, 10(1):73-84.

McLoughlin C, Lee MJW. 2007. Social software and participatory learning: Pedagogical choices with technology affordances in the Web 2.0 era. Paper presented at the Australasian Society for Computers in Learning in Tertiary Education Singapore.

Panda S 2010. Social software, Social Networks, and Online Distance Leaning. 4th Lecture in the ODL Occasional Lecture Series. Institute for Open and Distance Learning. University of South Africa.

Salaway G, Caruso JB, Nelson MR., Ellison NB. 2008. The ECAR Study of Undergraduate Students and Information Technology, 2008. Boulder, CO: EDUCAUSE Center for Applied Research.

Umbach PD, Wawrzynski MR. 2005. Faculty do matter: The role of college faculty in student learning and engagement. Research in Higher Education, 46(2), 153 - 185.

Van Wyk MM. 2013a. Exploring Students Perceptions of Blogs During Teaching Practice Placements. Mediterranean Journal of Social Sciences, Vol 4, no14. pp525-533. MCSER Publishing, Rome-Italy

Van Wyk MM. 2013b. Blogging as an E-learning tool in teaching economics. Theme of conference: The State of play in educational research in South Africa. Conference Proceeding of the South African Education Research Association, Klein Kariba. Cape Town Oxford University Press. pp.284-302.

Van Wyk MM. 2012. Narrating Student Teachers' Personal Stories in Relation to Identity, Social Class and Learning through a Schoolbased learning project. The International Journal on Diversity in Organizations, Communities and Nations, Volume 11 (2):111122. Common Ground Publishing Press, University of Illinois

Zhao CM, Kuh GD. 2004. Adding value: Learning communities and student engagement. Research in Higher Education, 45(2), 115-135. 